\title{
Empathy, cyberbullying, and cybervictimization among Filipino adolescents
}

\author{
Tadena Shannen ${ }^{1}$, Shin-Jeong Kim², Jungmin Lee ${ }^{3}$ \\ ${ }^{1}$ Graduate Student, School of Nursing, Hallym University, Chuncheon; ${ }^{2}$ Professor, School of Nursing, Research Institute of Nursing Science, Hallym University, \\ Chuncheon; ${ }^{3}$ Lecturer, School of Nursing, Hallym University, Chuncheon, Korea
}

Purpose: The purpose of this study was to gain insights into empathy, cyberbullying, and cybervictimization among Filipino adolescents. Methods: The participants were 168 junior high school students in the 7th to 10th grades at a public high school in Cavite Province, Philippines. Data were collected on demographic characteristics, the Basic Empathy Scale, and Revised Cyber Bullying Inventory-II scores. The data were analyzed in SPSS using descriptive statistics (frequency and mean), the independent t-test, bivariate correlation, and one-way analysis of variance. Results: The degree of empathy did not show a statistically significant relationship with cyberbullying $(\mathrm{r}=-.07, p=.359)$ but did show a significant relationship with cybervictimization $(\mathrm{r}=.18$, $p=.025)$. Furthermore, cyberbullying had a statistically significant association with cybervictimization ( $\mathrm{r}=.60, p<.001)$. Conclusion: Although empathy does not necessarily affect cyberbullying, higher levels of empathy were found among cyberbullying victims. However, an alarming result of this study is the possibility that victims may become cyberbullies. Therefore, we should highlight empathy as part of efforts to prevent cyberbullying and to solve various cyber-related problems. Since cyberbullying and cybervictimization are closely related, it is important to focus on this relationship and to make multilateral efforts to ensure that cyberbullying does not lead to other negative issues.

Key words: Adolescent; Cyberbullying; Cyber victimization; Empathy

\section{Corresponding author Shin-Jeong Kim \\ https://orcid.org/0000-0003-2582-3436 \\ School of Nursing, Hallym University, \\ 1 Hallymdaehak-gil, Chuncheon 24252, Korea \\ TEL +82-33-248-2721 FAX +82-33-248-2734 \\ E-MAIL ksj@hallym.ac.kr}

Received Dec 13, 2020 Revised Dec 25, 2020
Accepted Jan 5, 2021 (a) This is an Open Access article distributed under the terms of the Creative Commons Attribution NonCommercial License (http://creativecommons.org/licenses/by-nc/4.0/) which permits unrestricted noncommercial use, distribution, and reproduction in any medium, provided the original work is properly cited.

\section{INTRODUCTION}

Cyberbullying is more harmful than other types of violence because a negative post or comment can reach a limitless number of social media (SM) users, thereby increasing the opportunity of prolonged exposure and permanency $[1,2]$. Furthermore, younger generations currently tend to embrace the use of SM [1]. A term related to "cyberbullying" is "cybervictimization', which refers to the experience of being victimized through the use of electronic information on the internet [2]. Cyberbullying is considered to be a form of violent behavior; therefore, it is expected that cyberbullying causes detrimental effects for both the victim and the perpetrator.

The use of the internet for SM has steadily grown over time. As of January 2020, the estimated number of active SM users worldwide was 3.8 billion, reflecting an increase from the number of 3.4 billion in January 2019 [3]. In particular, during the coronavirus disease 2019 (COVID-19) pandemic, there has been an increase in the number of digital platform users [4]. Individuals are now actively posting their new achievements during the pandemic lockdown and expressing their opinions more vocally than before, as SM is now the most frequently used communication method for most individuals [4]. One study showed that as SM use increases, students who are 
prone to bullying are more likely to face cyberbullying [4]. There can be a limitless exchange of information among the SM users, and this information can sometimes be used in negative ways that may cause harm or make someone feel harassed. The act of harassing or harming someone via the use of SM is called cyberbullying. Cyberbullying can happen by sending harassing messages, posting derogatory comments on SM sites, posting humiliating pictures, and threatening someone electronically [5].

Victims of cyberbullying usually report feelings of depression, anger, frustration, and even suicidal thoughts. Cyberbullying has been found to be linked to low self-esteem, family problems, academic problems, violence, and delinquent behaviors [1,4]. In general, the estimated number of adolescents experiencing cyberbullying is around $10 \%-40 \%$, although the percentage depends on age and the definition of cyberbullying used in the study [1,2]. In the United States, among a sample of 5,700 middle to high school students, $33.8 \%$ admitted to being cyberbullied, while $11.5 \%$ admitted to being perpetrators of cyberbullying [1]. In South Korea, $10.8 \%$ of 50,000 elementary to high school students experienced cyberbullying [6]. In a survey conducted in the Philippines, it was found that $80 \%$ of 1,143 respondents aged $13-16$ years experienced cyberbullying [7].

A psychological factor related to the development of violent behavior is having a low empathy level. Empathy can be defined using two dimensions: cognitive and affective. Cognitive empathy is the ability to communicate, tolerate, recognize, and perceive emotions, while affective empathy refers to the ability to perceive and share both the positive and negative emotions of other people [8]. A study showed that lower levels of empathy increased the development of violent or aggressive behaviors, while a higher level of empathy decreased the development of violent or aggressive behaviors [9]. Since cyberbullying is considered to be a violent behavior, it is possible that empathy influences cyberbullying.

Adolescence is an important developmental stage when adolescents transition from childhood to adulthood. The changes experienced by adolescents also affect their roles in their family, with friends, and in their communities. Thus, it is vital to pay special attention to adolescents [10]. The parents of Filipino adolescents set the expectation that they are to be aware of their actions and the consequences corresponding to those actions [11]. Camaraderie is a factor valued by Filipino adolescents, which is why it is natural for them to be friendly, resulting in the expectation that they know how to empathize with someone [11]. Nonetheless, little research has discussed Filipino adolescents' characteristics, and although favorable characteristics have been mentioned, there has been an increase in cases of cyberbullying in the Philippines [7].
It has been reported that inhabitants of the Philippines spend an average of 4 hours a day using SM, exceeding the values reported for other countries [3]. Since prolonged exposure to SM can increase victimization, Filipinos may be exposed to the harmful effects of SM for a longer time than others [1]. Although there has been an increase in the number of cases of cyberbullying in the Philippines, little research has tackled this issue. Because of the detrimental effects of cyberbullying, it is important for adolescents to be aware of its seriousness and the importance of putting an end to this violent behavior. Since adolescence is a vital stage of life, it is important to properly guide adolescents throughout this period. To the researchers' knowledge, no published study has yet investigated empathy among Filipino adolescents and its possible influence on cyberbullying and cybervictimization.

\section{Purpose}

The purpose of this study was to investigate empathy, cyberbullying, and cybervictimization among Filipino adolescents, with the following specific goals:

- To identify the degree of empathy, cyberbullying, and cybervictimization among junior high school students.

- To identify differences in empathy, cyberbullying, and cybervictimization according to participants' general characteristics.

- To identify the relationships among empathy, cyberbullying, and degree of cybervictimization.

\section{Theoretical Framework}

Two theoretical frameworks were used to support the study: the social learning theory developed by Albert Bandura [12] and the general strain theory developed by Robert Agnew [13] (Figure 1).

Social learning theory [12] reflects the understanding that a person learns and develops attitudes, behaviors, and emotional reactions by observing others' actions. It combines cognitive and behavioral learning theory. Cyberbullying incidents and SM may influence ones' empathy due to what a person observes or experiences through SM. Along with other factors that may also affect someone's empathy, a person might, or might not, engage in cyberbullying .

General strain theory [13] supports the assumption that negative experiences can lead to strain or stress. Victimization is considered a stressful experience, and according to this theory, experiences of stress or strain may cause a person to perform a positive or negative action to decrease the stress or strain. Within this framework, the study used general strain theory to investigate whether cybervictimization increased 


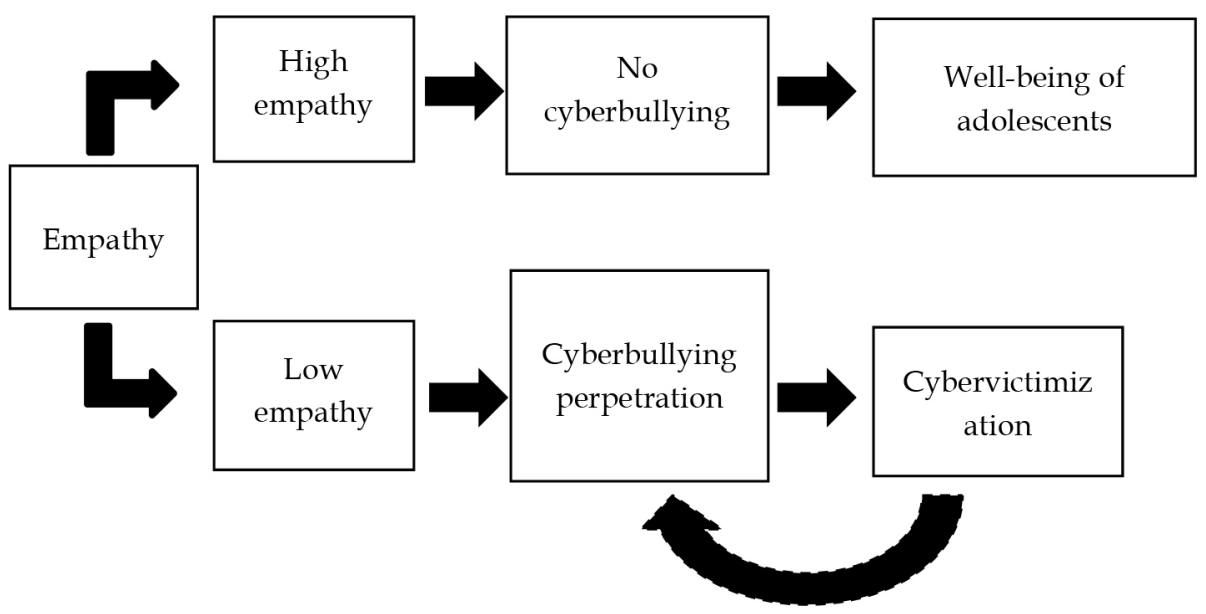

Figure 1. Empathy, cyberbullying, and cybervictimization framework.

victims' likelihood to engage in cyberbullying as a response to the strain that they experienced.

\section{METHODS}

\section{Study Design}

This research is a descriptive study using a questionnaire to investigate empathy, cyberbullying, and cybervictimization among Filipino adolescents.

\section{Participants}

The participants were junior high school students who were currently enrolled in a public secondary school in Cavite Province, Philippines. Junior high school is the term used in the Philippines to describe grade 7 to 10 students, whereas in South Korea, the term middle or high school is used. The participants were students from grades 7 to 10 who were aged 12 to 19 years old and used SM applications. The school was selected using convenience sampling. The sample size for the correlation was calculated using $G^{*}$ Power 3.1.9.2. The results indicated that 164 participants were needed for an effect size of .25, a significance level of .05 , and a test power of .95 . Anticipating an $80 \%$ response rate, 201 participants were recruited. Responses from 168 participants were analyzed after excluding uncompleted questionnaires.

\section{Measurements}

\section{1) Empathy}

The Basic Empathy Scale was developed by Jolliffe and Farrington [14] and validated among 363 adolescents (grade 10) in the United Kingdom. The scale is a 20-item instrument with two subscales (cognitive empathy with 9 items, Cronbach's $\alpha=.79$; affective empathy with 11 items, Cronbach's $\alpha$ $=.85$ ). It is a 5 -point Likert-type scale (strongly disagree $=1$, disagree $=2$, neutral $=3$, agree $=4$, and strongly agree $=5$ ). Eight items are reverse-scored. A higher score indicates a higher empathy level [14]. For the current study, four items were omitted to obtain a more acceptable Cronbach's $\alpha$. Each of the eight items was used to measure cognitive empathy and affective empathy. Cronbach's $\alpha$ values of .67 for the complete empathy scale, .51 for cognitive empathy, and .52 for affective empathy were recorded. Cronbach's $\alpha$ values ranging from .50 to .75 are generally accepted because these values indicate moderate reliability [15]. The researcher conducted a pilot study without omitting the four questions and recorded a Cronbach's $\alpha$ of .79 for the complete empathy scale, .67 for cognitive empathy, and .65 for affective empathy. After omitting the four questions, Cronbach's $\alpha$ values of .81 for the complete empathy scale, .80 for cognitive empathy, and .66 for affective empathy were recorded.

\section{2) Cyberbullying and cybervictimization}

The Revised Cyber Bullying (Cyber Victim) Inventory-II is the second revision of the tool developed by Topcu and Erdur-Baker [16] and validated among 1,803 high school students attending public high school in Ankara, Turkey. The purpose of the revision was to update and eliminate specific technology names. Consisting of 10 items, participants rate each item twice (once for reporting cyberbullying experience and once for reporting cybervictimization) on a 4-point rating scale $(1=$ never, $2=$ once, $3=$ twice or three times, $4=$ more than three times). Scores are added to achieve the total score in each form. A total score of 10 means being not involved in cyberbullying or cybervictimization, respectively, whereas a higher score indicates more frequent engagement in cy- 
berbullying and cybervictimization. The Cronbach's $\alpha$ coefficients were .80 for the cybervictimization part and .79 for the cyberbullying part [17]. In this study, Cronbach's $\alpha$ values of .80 for cyberbullying and .75 for cybervictimization were recorded. A pilot study recorded a Cronbach's $\alpha$ of .88 for the entire questionnaire, .57 for the cyberbullying subscale, and .92 for the cybervictimization subscale.

\section{3) Content validity index}

The modified questionnaire used in this study to measure empathy was reviewed and approved by a group of experts, including two professors from the child and adolescent department and three nurses who had both worked in a pediatric unit at a university hospital for over 5 years and had doctoral degrees in nursing. The content validity index was .91 using the rating of item relevance.

\section{Data Collection Method}

After receiving approval to conduct the study from the Institutional Review Board of Hallym University, the researcher coordinated with a teacher at a public secondary school in the Philippines. The researcher was endorsed by the school principal, and a letter describing the timetable for gathering data, the research tools, the purpose of the study, and permission to conduct the study was personally given. After receiving permission to conduct the study, endorsement letters, student and parental consent forms were distributed to the students and were signed by both the student and parents as proof that they agreed to participate in the study. After receiving the consent forms, a pilot study was conducted among two students from each grade level to assess the validity of the tool. After validation, the researcher collected data by distributing the questionnaires, giving instructions, and remaining in the classroom for the duration of questionnaire completion be able to respond to any questions or clarification from the participants. It took around 15 minutes for each class to complete the questionnaires. The collected questionnaires were kept and locked in the cabinet of the corresponding author's research room and were not accessible to any other researchers.

\section{Ethical Considerations}

The two instruments used in this study were approved for use by the original authors through email. In addition, the study was conducted after receiving approval from the Institutional Review Board of Hallym University (HIRB-2019092). The study was conducted at a public secondary school. The researcher explained the purpose and procedure of the re- search to the participants who agreed to participate by completing an informed consent form. Assurance was given that the results of the study would only be used for the current study and that the anonymity of the participants would be maintained. Participants were provided snacks worth about $\$ 1$ per person as compensation.

\section{Statistical Analysis}

Data were analyzed using SPSS for Windows version 25 (IBM Corp., Armonk, NY, USA). Participants' demographic characteristics were analyzed in terms of percentage, frequency, and mean \pm standard deviation. The Shapiro-Wilk hypothesis test and the Levene test for equality of variance were performed to confirm the normality of the distribution and within-group normality. The t-test and analysis of variance were conducted to identify differences in empathy, cyberbullying, and cybervictimization according to participants' characteristics. The Duncan multiple range test was used to determine specific differences between pairs of means. Bivariate correlation analysis was conducted to assess the relationships among empathy, cyberbullying, and cybervictimization

\section{RESULTS}

\section{Descriptive Characteristics of the Participants}

The descriptive characteristics of the participants are shown in Table 1. Of the 168 participants, $44.0 \%(n=74)$ were male and $56.0 \%(n=94)$ were female, and their ages were $12-19$ years old, with a mean of $14.3 \pm 1.4$ years. Forty-four $(26.2 \%)$ of the participants were in the 10th grade, followed by $25.6 \%$ $(n=43)$ in eighth grade, $24.4 \%(n=41)$ in seventh grade, and $23.8 \%(n=40)$ in the ninth grade. The most commonly utilized SM platform by the participants was Facebook $(98.8 \%$; n= 166). The average time of SM usage per day was $296.1 \pm 266.1$ minutes (4.93 hours or almost 5 hours). Among the 168 participants, the majority used SM applications more than seven times per day $(n=57,34.3 \%)$, followed by three to four times $(n=46,27.7 \%)$, five to six times $(n=39,23.5 \%)$, and one to two times $(n=24,14.5 \%)$. The cell phone was the primary device used to check SM platforms ( $\mathrm{n}=154,91.7 \%)$. The predominant purpose of using SM was to watch videos $(n=121,72.0 \%)$, while the least common purpose was to read articles $(n=62$, $36.9 \%)$.

\section{Degree of Empathy, Cyberbullying, and Cybervictimi- zation}

The content, mean score, and standard deviation of the 
Basic Empathy Scale and Revised Cyber Bullying Inventory-II are presented in Table 2 . The total mean score for empathy was $3.4 \pm 0.4$ out of 5 , indicating a high level of empathy among the participants. The item with the highest mean score was "I can understand my friend's happiness when she/he does well at something" (3.7 \pm 1.1$)$. Followed by "When someone is feeling 'down' I can usually understand how they feel" (3.6 \pm 1.2$)$, "I often become sad when watching sad things on or in films" (3.6 \pm 1.3$)$, "I can often understand how people are feeling even before they tell" (3.7 \pm 1.1$)$, and "I can usually

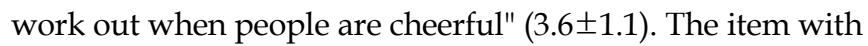
the lowest mean score was "I find it hard to know when my friends are frightened" (2.8 \pm 1.1$)$. The average score was divided by 10 which is the number of items. Thus, for cyberbullying was $1.6 \pm 0.5$, and that for cybervictimization was $1.7 \pm 0.6$ out of 4 , which indicated the existence of cyberbullying and cybervictimization, with a slightly higher score for the latter. "Insulting someone [on the internet]" was the item with the highest average score (1.9 \pm 1.0 for cyberbullying and 2.1 \pm 1.1 for cybervictimization), followed by "taking over the password of someone's account [on the internet]" $(1.8 \pm 0.9$ for cyberbullying and $1.8 \pm 0.9$ for cybervictimization). "Creating a humiliating website [on the internet]" showed the lowest mean score (1.1 \pm 0.5 for cyberbullying and $1.2 \pm 0.6$ for cybervictimization).

\section{Differences in the Level of Empathy, Cyberbullying, and Cybervictimization According to Participants' General Characteristics}

Patterns in empathy, cyberbullying and cybervictimization according to participants' general characteristics are shown in Table 3. Total empathy, cognitive empathy, and affective empathy were significantly higher among female participants than among male participants $(\mathrm{t}=3.82, p<.001, \mathrm{t}=2.19, p=.030$, and $\mathrm{t}=4.05, p=.001$, respectively). However, there were no significant differences in cyberbullying and cybervictimization by gender $(\mathrm{t}=0.20, p=.838$, and $\mathrm{t}=0.35, p=.724$, respectively).

There was a statistically significant difference in total empathy and both cognitive and affective empathy according to grade level $(\mathrm{F}=3.90, p=.010, \mathrm{~F}=3.80, p=.012$, and $\mathrm{F}=3.45, p=$ .010 , respectively). Empathy was significantly higher among grade 10 students than among students of the other grade levels, but the Duncan post hoc test showed no significant difference in the mean scores. In addition, participants' grade showed a statistically significant association with cyberbullying $(\mathrm{F}=3.03, p=.031)$. Cyberbullying was significantly more common among students in grade 8 than among students of the other grade levels, but the Duncan post hoc test showed no significance. In addition, cybervictimization showed a statisti- cally significant difference according to grade level ( $\mathrm{F}=7.66$, $p<.001$ ), and was also higher in grade 8 participants, but the Duncan post hoc test showed no significance.

Statistically significant differences in total empathy and both cognitive and affective empathy were found according to participants' age $(\mathrm{t}=2.86, p=.005, \mathrm{t}=2.67, p=.008$, and $\mathrm{t}=2.51$, $p=.013$, respectively). There were no significant differences in cyberbullying or cybervictimization by age $(\mathrm{t}=0.59, p=.558$, and $t=1.13, p=.262$, respectively). Finally, there were no significant differences in any dependent variables according to the daily use of SM.

Table 1. Demographic Characteristics of Participants $(N=168)$

\begin{tabular}{|c|c|c|}
\hline Characteristics & Categories & $\begin{array}{c}\mathrm{n}(\%) \\
\mathrm{M} \pm \mathrm{SD}\end{array}$ \\
\hline Gender & $\begin{array}{l}\text { Male } \\
\text { Female }\end{array}$ & $\begin{array}{l}74(44.0) \\
94(56.0)\end{array}$ \\
\hline Age (year) * & $\begin{array}{l}12-15 \\
16-19\end{array}$ & $\begin{array}{c}14.3 \pm 1.4 \\
129(77.7) \\
37(22.3)\end{array}$ \\
\hline Grade & $\begin{array}{l}\text { 7th } \\
8 \text { th } \\
9 \text { th } \\
10 \text { th }\end{array}$ & $\begin{array}{l}41(24.4) \\
43(25.6) \\
40(23.8) \\
44(26.2)\end{array}$ \\
\hline $\begin{array}{l}\text { What SM/SNS } \\
\text { platform(s) } \\
\text { do you use }^{\dagger}\end{array}$ & $\begin{array}{l}\text { Facebook } \\
\text { Instagram } \\
\text { Messenger } \\
\text { Others } \\
\text { Skype } \\
\text { Snapchat } \\
\text { TikTok } \\
\text { Tumblr } \\
\text { Twitter }\end{array}$ & $\begin{array}{c}166(98.8) \\
64(38.1) \\
123(73.2) \\
21(12.5) \\
2(1.2) \\
86(51.2) \\
61(36.3) \\
7(4.2) \\
43(25.6)\end{array}$ \\
\hline Time usage (minute) & & $296.1 \pm 266.1$ \\
\hline $\begin{array}{l}\text { Daily use } \\
\text { (time)* }^{*}\end{array}$ & $\begin{array}{l}1-2 \\
3-4 \\
5-6 \\
\geq 7\end{array}$ & $\begin{array}{l}24(14.5) \\
46(27.7) \\
39(23.5) \\
57(34.3)\end{array}$ \\
\hline $\begin{array}{l}\text { The device } \\
\text { used to } \\
\text { check SM }{ }^{\dagger}\end{array}$ & $\begin{array}{l}\text { Cell phone } \\
\text { Laptop/personal } \\
\text { Computer } \\
\text { Tablet/iPad }\end{array}$ & $\begin{array}{c}154(91.7) \\
48(28.6) \\
21(12.5) \\
5(3.0)\end{array}$ \\
\hline $\begin{array}{l}\text { Purpose of } \\
\text { using } \mathrm{SM}^{\dagger}\end{array}$ & $\begin{array}{l}\text { Communication } \\
\text { Educational purposes } \\
\text { Posting pictures } \\
\text { Reading articles } \\
\text { Updating oneself on } \\
\text { the latest news } \\
\text { Watching video }\end{array}$ & $\begin{array}{l}106(63.1) \\
73(43.5) \\
97(57.7) \\
62(36.9) \\
84(50.0) \\
121(72.0)\end{array}$ \\
\hline
\end{tabular}

${ }^{*}$ Missing data were not included; ${ }^{\dagger}$ Multiple choice; SM, social media; SNS, social networking site. 
Table 2. Empathy, Cyberbullying, and Cybervictimization of the Participants $(N=168)$

\begin{tabular}{|c|c|c|c|c|}
\hline Variable & Categories & \multicolumn{2}{|l|}{ Contents } & $\mathrm{M} \pm \mathrm{SD}$ \\
\hline \multirow[t]{3}{*}{ Empathy } & $\begin{array}{l}\text { Cognitive } \\
\text { empathy }\end{array}$ & $\begin{array}{l}\text { I can understand my friend's happiness when she/he does we } \\
\text { I find it hard to know when my friends are frightened.* } \\
\text { When someone is feeling 'down' I can usually understand hov } \\
\text { I can usually work out when my friends are scared. } \\
\text { I can often understand how people are feeling even before the } \\
\text { I can usually work out when people are cheerful. } \\
\text { I am not usually aware of my friend's feelings.* } \\
\text { I have trouble figuring out when my friends are happy.* } \\
\text { Sub total }\end{array}$ & $\begin{array}{l}\text { mething. } \\
\text { feel. } \\
\text { ne. }\end{array}$ & $\begin{array}{l}3.7 \pm 1.1 \\
2.8 \pm 1.1 \\
3.6 \pm 1.2 \\
3.1 \pm 1.0 \\
3.6 \pm 1.1 \\
3.6 \pm 1.1 \\
3.4 \pm 1.2 \\
3.0 \pm 1.2 \\
3.4 \pm 0.5\end{array}$ \\
\hline & $\begin{array}{l}\text { Affective } \\
\text { empathy }\end{array}$ & \multicolumn{2}{|c|}{$\begin{array}{l}\text { My friend's emotions don't affect me much.* } \\
\text { After being with a friend who is sad about something, I usually feel sad. } \\
\text { I get caught up in other people's feelings easily. } \\
\text { Other people's feelings don't bother me at all.* } \\
\text { I often become sad when watching sad things on or in films. } \\
\text { Seeing a person who has been angered has no effect on my feelings.* } \\
\text { I tend to feel scared when I am with friends who are afraid. } \\
\text { I often get swept up in my friend's feelings. } \\
\text { Sub total }\end{array}$} & $\begin{array}{l}3.3 \pm 1.2 \\
3.5 \pm 1.0 \\
3.2 \pm 1.1 \\
3.3 \pm 1.2 \\
3.6 \pm 1.3 \\
3.0 \pm 1.1 \\
3.0 \pm 1.0 \\
3.3 \pm 1.0 \\
3.3 \pm 0.5\end{array}$ \\
\hline & \multicolumn{3}{|l|}{ Total } & $3.4 \pm 0.4$ \\
\hline \multirow[t]{2}{*}{ Variable } & \multirow{2}{*}{\multicolumn{2}{|c|}{ Contents }} & $\begin{array}{l}\text { Cyber } \\
\text { bullying }\end{array}$ & $\begin{array}{c}\text { Cyber } \\
\text { victimization }\end{array}$ \\
\hline & & & $\mathrm{M} \pm \mathrm{SD}$ & $\mathrm{M} \pm \mathrm{SD}$ \\
\hline \multirow{11}{*}{$\begin{array}{l}\text { Cyberbullying and } \\
\text { cybervictimization }\end{array}$} & \multicolumn{2}{|c|}{ [On the internet] taking over the password of someone's account. } & $1.8 \pm 0.9$ & $1.8 \pm 0.9$ \\
\hline & \multicolumn{2}{|c|}{ [On the internet] using someone's account without his/her permission. } & $1.5 \pm 0.8$ & $1.6 \pm 0.9$ \\
\hline & \multicolumn{2}{|c|}{ [On the internet] threatening someone. } & $1.4 \pm 0.8$ & $1.7 \pm 0.9$ \\
\hline & \multicolumn{2}{|c|}{ [On the internet] insulting someone. } & $1.9 \pm 1.0$ & $2.1 \pm 1.1$ \\
\hline & \multicolumn{2}{|c|}{ [On the internet] sending embarrassing and hurtful messages. } & $1.7 \pm 0.9$ & $1.8 \pm 1.0$ \\
\hline & \multicolumn{2}{|c|}{$\begin{array}{l}\text { [On the internet] sharing an inappropriate photo or a video of someone } \\
\text { without his/her permission. }\end{array}$} & $1.5 \pm 0.8$ & $1.7 \pm 0.9$ \\
\hline & \multicolumn{2}{|c|}{$\begin{array}{l}\text { [On the internet] sharing a secret with others without the permission of the } \\
\text { owner. }\end{array}$} & $1.6 \pm 0.8$ & $1.8 \pm 0.9$ \\
\hline & \multicolumn{2}{|c|}{ [On the internet] spreading rumors. } & $1.5 \pm 0.7$ & $1.7 \pm 0.9$ \\
\hline & \multicolumn{2}{|c|}{$\begin{array}{l}\text { [On the internet] creating an account on behalf of someone without letting } \\
\text { him/her know and acting like the account's owner. }\end{array}$} & $1.3 \pm 0.7$ & $1.4 \pm 0.8$ \\
\hline & \multicolumn{2}{|c|}{ [On the internet] creating a humiliating website. } & $1.1 \pm 0.5$ & $1.2 \pm 0.6$ \\
\hline & \multicolumn{2}{|l|}{ Total } & $1.6 \pm 0.5$ & $1.7 \pm 0.6$ \\
\hline
\end{tabular}

*Reverse items.

\section{Correlations among Empathy, Cyberbullying, and Cybervictimization}

Cybervictimization was significantly correlated with participants' total empathy $(\mathrm{r}=.18, p=.025)$ and cognitive empathy $(\mathrm{r}=.17, p=.030)$, but not with affective empathy $(\mathrm{r}=.12, p=.114)$. Total empathy was not significantly correlated with cyberbullying ( $\mathrm{r}=-.07, p=.359)$. Cyberbullying was significantly correlated with cybervictimization $(\mathrm{r}=.60, p<.001)$ (Table 4$)$.

\section{DISCUSSION}

The Philippines has a total population of 108 million, of whom 73 million are active SM users $[3,18]$. In the current study, Facebook was the most used SM application used by adolescents. In 2020, Facebook had approximately of 2.4 billion monthly users worldwide, thus making it the most popular SM application [3]. In the Philippines, Facebook is currently the most popular SM application, with at least 70 mil- 
Table 3. Differences in Participants' Empathy, Cyberbullying, and Cybervictimization According to Their Characteristics $(N=168)$

\begin{tabular}{|c|c|c|c|c|c|c|c|c|c|c|c|}
\hline \multirow{2}{*}{ Characteristics } & \multirow{2}{*}{ Categories } & \multicolumn{2}{|c|}{ Cognitive empathy } & \multicolumn{2}{|c|}{ Affective empathy } & \multicolumn{2}{|c|}{ Empathy (total) } & \multicolumn{2}{|c|}{ Cyberbullying } & \multicolumn{2}{|c|}{ Cybervictimization } \\
\hline & & $\mathrm{M} \pm \mathrm{SD}$ & $t$ or $F(p)$ & $\mathrm{M} \pm \mathrm{SD}$ & tor $F(p)$ & $\mathrm{M} \pm \mathrm{SD}$ & tor $F(p)$ & $\mathrm{M} \pm \mathrm{SD}$ & $\operatorname{tor} F(p)$ & $\mathrm{M} \pm \mathrm{SD}$ & t or F $(p)$ \\
\hline \multirow[t]{2}{*}{ Gender } & Male & $27.0 \pm 4.4$ & 2.19 & $25.6 \pm 3.9$ & 405 & $52.7 \pm 7.0$ & 3.82 & $15.7 \pm 4.4$ & 0.20 & $16.9 \pm 6.3$ & 0.35 \\
\hline & Female & $28.5 \pm 4.3$ & $(.030)$ & $28.4 \pm 4.3$ & $(.001)$ & $57.3 \pm 7.7$ & $(<.001)$ & $15.5 \pm 4.4$ & $(.838)$ & $17.2 \pm 5.0$ & $(.724)$ \\
\hline \multirow[t]{4}{*}{ Grade } & $7 \mathrm{th}^{\mathrm{a}}$ & $26.2 \pm 4.7$ & 3.80 & $25.3 \pm 4.9$ & 3.45 & $51.9 \pm 8.0$ & 3.90 & $14.0 \pm 3.9$ & 3.03 & $15.0 \pm 5.2$ & 7.66 \\
\hline & $8 \mathrm{th}^{\mathrm{a}}$ & $27.7 \pm 4.6$ & $(.012)$ & $27.3 \pm 4.6$ & $(.010)$ & $55.2 \pm 7.8$ & $(.010)$ & $16.9 \pm 5.0$ & $(.031)$ & $19.6 \pm 6.9$ & $(<.001)$ \\
\hline & 9 th $^{\mathrm{a}}$ & $27.5 \pm 3.8$ & & $27.5 \pm 4.5$ & & $55.1 \pm 7.0$ & & $15.2 \pm 3.8$ & & $15.2 \pm 4.3$ & \\
\hline & $10 t^{b}$ & $29.5 \pm 3.9$ & & $28.4 \pm 3.9$ & & $57.9 \pm 7.1$ & & $16.1 \pm 4.5$ & & $18.3 \pm 4.4$ & \\
\hline \multirow[t]{2}{*}{ Age (year) } & $12-15$ & $27.3 \pm 4.4$ & 2.67 & $26.7 \pm 4.7$ & 2.51 & $54.3 \pm 7.7$ & 2.86 & $15.3 \pm 4.1$ & 0.59 & $16.7 \pm 5.8$ & 1.13 \\
\hline & $16-19$ & $29.5 \pm 3.7$ & $(.008)$ & $28.8 \pm 3.9$ & $(.013)$ & $58.4 \pm 7.0$ & $(.005)$ & $15.8 \pm 4.8$ & $(.558)$ & $17.9 \pm 4.6$ & $(.262)$ \\
\hline \multirow{4}{*}{$\begin{array}{l}\text { Daily use } \\
\text { (time) }\end{array}$} & $1-2$ & $26.96 \pm 4.35$ & 0.60 & $25.79 \pm 4.19$ & 1.05 & $52.65 \pm 7.53$ & 0.92 & $14.42 \pm 3.05$ & 0.71 & $15.42 \pm 3.96$ & 1.37 \\
\hline & $3-4$ & $26.86 \pm 4.59$ & $(.615)$ & $26.09 \pm 4.15$ & $(.372)$ & $53.19 \pm 7.63$ & $(.434)$ & $15.65 \pm 4.17$ & $(.547)$ & $17.04 \pm 5.29$ & $(.253)$ \\
\hline & $5-6$ & $26.73 \pm 3.44$ & & $26.85 \pm 3.49$ & & $53.54 \pm 6.38$ & & $15.90 \pm 4.71$ & & $16.67 \pm 5.73$ & \\
\hline & $\geq 7$ & $27.71 \pm 3.55$ & & $27.10 \pm 3.98$ & & $55.06 \pm 6.29$ & & $15.91 \pm 5.01$ & & $18.11 \pm 6.50$ & \\
\hline
\end{tabular}

*Duncan post hoc test: $\mathrm{a}<\mathrm{b}$.

Table 4. Correlations among Empathy, Cyberbullying, and Cybervictimization $(N=168)$

\begin{tabular}{|c|c|c|c|c|c|c|}
\hline \multirow{2}{*}{ Variables } & & \multicolumn{3}{|c|}{ Empathy } & \multirow{2}{*}{ Cyberbullying } & \multirow{2}{*}{ Cybervictimization } \\
\hline & & Cognitive empathy & Affective empathy & Total & & \\
\hline \multirow[t]{2}{*}{ Empathy } & Cognitive empathy & 1 & & & & \\
\hline & $\begin{array}{l}\text { Affective empathy } \\
\text { Total }\end{array}$ & $.86(<.001)$ & $\begin{array}{c}1 \\
.87(<.001)\end{array}$ & 1 & & \\
\hline \multicolumn{2}{|c|}{ Cyberbullying } & $.03(.753)$ & $-.09(.274)$ & $-.07(.359)$ & 1 & \\
\hline \multicolumn{2}{|c|}{ Cybervictimization } & $.17(.030)$ & $.12(.114)$ & $.18(.025)$ & $.60(<.001)$ & 1 \\
\hline
\end{tabular}

lion users, and most SM users use cellphones to access SM; this trend was also found in a study conducted among Filipino adolescents [18]. The Philippines have had the longest average daily time of SM use for 4 consecutive years, which reached 4 hours in 2020 [3]. This finding is in line with the current study, which recorded an average of almost 5 hours of $\mathrm{SM}$ use. Most respondents used SM to watch videos $(\mathrm{n}=121)$ and for communication $(n=106)$. Watching videos and communication were also the top 2 purposes of using SM in an earlier study [18].

Filipinos have been observed to value camaraderie and find it natural to be friendly to others, for which reason they place considerable importance on interpersonal relationships [11]. The importance placed on friendship may be interpreted as reflecting a high level of empathy among Filipino adolescents. The existence of cyberbullying and cybervictimization was evident according to the findings of the study. Even with the increase in cyberbullying in the Philippines, some undocumented cases may exist due to victims' fear of their situation being publicized. Some schools also tend to under-report cyberbullying due to fears of tarnishing the school's reputation
[19].

Demographic characteristics are believed to possibly influence empathy, cyberbullying, and cybervictimization. A significant relationship was found between empathy and gender in the current study, with female adolescents scoring higher for empathy than male adolescents. This may result from gender expectations in Filipino culture between the two genders. Female adolescents are expected to help their mothers with chores and to take care of their siblings, which fosters nurturing characteristics and helps them to understand different emotions. In contrast, male adolescents are trained to be logical and independent, and to keep their emotions to themselves [20]. This may explain why the female participants in this study had a higher degree of empathy than the male participants. However, no significant relationship was found between cyberbullying or cybervictimization and gender, similar to another study conducted in the Philippines [21]. These results show that when considering factors influencing empathy, other demographic characteristics such as age, educational level, and economic level must also be considered, as well as gender. Thus, further research is needed to predict the 
variables that affect Filipino adolescents' empathy regarding cyberbullying and cybervictimization.

The current study established a significant relationship between age and empathy. Another study also reported a similar result, and this relationship reflects the development of empathy, which grows with age until it reaches full development in adolescence [22]. However, some studies have reported a decrease in cognitive empathy and an increase in affective empathy in the elderly. A decrease in cognitive empathy may be related to reduced activity in brain areas associated with cognitive function [23].

No significant relationship was found between age and cybervictimization or cyberbullying in this study. This finding is similar to a study conducted among Filipino university students, where it was found that cyberbullying and cybervictimization experiences of students were not significantly related to their age [24].

There is scarce evidence regarding the relationships among grade level, empathy, cyberbullying, and cybervictimization. The current study identified a significant relationship between grade level and empathy, as well as with cyberbullying and cybervictimization. A study among grade 7-12 students found that the cognitive empathy of victims of cyberbullying was high [25]. However, in a comparison of cognitive empathy in cyberbully-victims (a term for victims who also engaged in cyberbullying) and bystanders, lower grade levels had higher levels of cognitive empathy than other groups, while higher grade levels had higher levels of cognitive empathy only among cyberbully-victims, but not bystanders. Furthermore, it was found that victimization increased after grade 7 and continued through grade 12 [25].

Empathy has consistently shown a negative relationship with antisocial behavior [15], implying that empathy may have a possible influence on cyberbullying. A study investigating the relationship between cyberbullying and empathy found out that a low level of both cognitive and affective empathy predicted cyberbullying [26]. The current study found no significant relationship between empathy and cyberbullying. The same result was found in another study, and a possible explanation for this result is that even though the participants had a high empathy level, which may make them sensitive to others' emotions, they may have viewed cyberbullying as a normal phenomenon [27]. As such, it is crucial to provide Filipino adolescents with the necessary information to protect themselves against cyberbullying. In addition, active interest and participation of parents and teachers are needed for the development of programs, practices, and policies to protect and support this population from this problem.

Few studies have reported a relationship between empathy and cybervictimization. It was found that cybervictims scored higher than cyberbullies and uninvolved students or bystanders in both cognitive and affective empathy [28]. One study reported higher affective empathy among cybervictims [29]. Another study reported significant relationships of both cognitive and affective empathy with cybervictimization [30]. In the current study, total empathy and cognitive empathy, but not affective empathy, had significant relationships with cybervictimization. This finding of distinct relationships of cognitive and affective empathy with cybervictimization was not found in previous research. The significant relationship between cybervictimization and cognitive empathy may be explained by cybervictims' capability to understand the perspective of others, while still having problematic social relationships, as shown by the lack of a significant association between affective empathy and cybervictimization. Furthermore, affective empathy is important in establishing social relationships [27].

Taking revenge is a possible response of a cybervictim to his or her bullies. The desire to take revenge may lead a cybervictim to engage in cyberbullying [30]. Another explanation is the application of general strain theory, which was developed by Agnew [13]. Greater exposure or experiences of cyberbullying may increase the likelihood that cybervictims will engage in cyberbullying to release their stress. This is an example of a negative response to strain. A study conducted in the Philippines and Turkey reported a positive relationship between cyberbullying and cybervictimization [21]. The current study yielded a significant relationship between cyberbullying and cybervictimization.

Several limitations were found in this study. The first is the length of the duration of data collection, which resulted in a small sample of participants from a single school. The second is that the researcher used convenience sampling to choose where to conduct the study and the participants to be included. Participants were picked by the teachers due to their availability and knowledge regarding SM use. The third is the use of a self-report survey. There is a possibility that students over-reported or misreported some data (e.g., SM time usage per day and the reasons for SM usage). The questionnaires used may have made the students feel discomfort, anxiety, and fear due to the questions. The fourth is the scarcity of articles about empathy, cyberbullying, cybervictimization, and characteristics of Filipino adolescents. The fifth is the reliability of the Basic Empathy Scale. This study recorded Cronbach's $\alpha$ values of . 67 for the total Basic Empathy Scale, .51 for the cognitive empathy subscale, and .52 for the affective empathy subscale. This is considered a low reliability score, but according to a book by Hinton et al. [15], a Cronbach's $\alpha$ value ranging from .50 to .75 is accepted because it indicates moderate reliability. 
Despite the limitations of this study, it still made a pertinent contribution to the study of empathy, cyberbullying, and cybervictimization.

\section{CONCLUSION}

The findings of this study shed important light on the issues of cyberbullying and cybervictimization, which could become more problematic in the COVID-19 pandemic. Empathy was not found to be negatively associated with cyberbullying. This can be explained by a lack of self-awareness, because some SM users post or send whatever they want without thinking about whether the content can harm others [1]. It is also possible that cyberbullying was viewed as a normal phenomenon, especially as SM use has increased over time. Cognitive empathy, but not affective empathy, was significantly associated with cybervictimization. It is possible for cybervictims to understand the emotions of others but still have difficulty in establishing social relationships or feeling the emotions of other people. The finding of this study that cyberbullying was significantly associated with cybervictimization is alarming. This relationship may be explained by the stress that cybervictims experience and their desire to take revenge on the perpetrators, especially since SM can be anonymously.

We expect that the findings of this study may contribute to the prevention of cyber-related problems among adolescents as it offers basic guidelines. Since adolescence can be a confusing period due to changes and transitions from childhood to adulthood, adolescents deserve special attention and guidance from people surrounding them. It is vital for parents, teachers, and even guardians to establish open and good communication with adolescents to properly guide them towards betterment. At this time, with one's capacity to empathize, it is possible to become a bystander or a defender of a victim, for which reason we should highlight empathy in efforts to prevent and solve various types of cyber-related problems. We also suggest that as cyberbullying and cybervictimization are closely related, it is important to focus on this relationship and to make multilateral efforts to ensure that cyberbullying does not lead to other negative problems.

\section{Conflict of interest}

No existing or potential conflict of interest relevant to this article was reported.

\section{Data availability}

Please contact the corresponding author for data availability.

\section{REFERENCES}

1. Patchin JW, Hinduja S. Summary of our cyberbullying research (2007-2019) [Internet]. Cyberbullying Research Center; 2019 [cited 2020 October 16]. Available from:

https://cyberbullying.org/summary-of-our-cyberbullying-research

2. Mohammed AM, Benson V, Saridakis G. Understanding the relationship between cybercrime and human behavior through criminological theories and social networking sites. In: Mehdi KhosrowPour DBA, editor. Encyclopedia of criminal activities and the deep web. Hershey, PA: IGI Global; 2020. p. 979-989.

3. Kemp S. Digital 2019: Global internet use accelerates [Internet]. New York, NY: We Are Social; 2019 [cited 2020 October 16]. Available from:

https://wearesocial.com/blog/2019/01/digital-2019-global-inter net-use-accelerates

4. Jain O, Gupta M, Satam S, Panda S. Has the COVID-19 pandemic affected the susceptibility to cyberbullying in India? Computers in Human Behavior Reports. 2020;2:1-9.

https://doi.org/10.1016/j.chbr.2020.100029

5. Nixon C. Current perspectives: The impact of cyberbullying on adolescent health. Adolescent Health, Medicine and Therapeutics. 2014;5:143-158. https://doi.org/10.2147/AHMT.S36456

6. Jung HM. Cyberbullying - Silent killer of students [Internet]. Seoul: The Korea Times; 2018 [cited 2020 October 16]. Available from: https://www.koreatimes.co.kr/www/nation/2018/11/181_256 314.html

7. Takumi R. $80 \%$ of young teens in PHL experience cyberbullying -Survey [Internet]. Quezon: GMA News Online; 2016 [cited 2020 October 16]. Available from:

https://www.gmanetwork.com/news/lifestyle/parenting/5608 86/80-of-young-teens-in-phl-experience-cyberbullying-survey/st ory

8. Vezzali L, Hewstone M, Capozza D, Trifiletti E, Bernardo GAD. Improving intergroup relations with extended contact among young children: Mediation by intergroup empathy and moderation by direct intergroup contact. Journal of Community and Applied Social Psychology. 2017;27(1):35-49.

https://doi.org/10.1002/casp.2292

9. Shechtman Z. Group intervention with aggressive children and youth through bibliotherapy. International Journal of Group Psychotherapy. 2017;67(1):47-67. https://doi.org/10.1080/00207284.2016.1202682

10. Ogena NB. A development concept of adolescence: The case of adolescents in the Philippines. Philippine Population Review. 2004; 3(1):1-18.

11. Medina BTG. The Filipino family. 2nd ed. Diliman: University of the Philippines Press; 2001.

12. Bandura A. Social learning theory. Bergen: Prentice Hall; 1977.

13. Agnew R. General Strain Theory: Current status and directions for 
further research. In: Cullen FT, Wright JP, Blevins KR, editors. Taking stock: The status of criminological theory. Piscataway, NJ: Transaction Publishers; 2006. p. 101-123.

14. Jolliffe D, Farrington D. Development and validation of the basic empathy scale. Journal of Adolescence. 2006;29(4):589-611. https://doi.org/10.1016/j.adolescence.2005.08.010

15. Hinton P, McMurray I, Brownlow C. SPSS Explained. 2nd ed. London: Routledge; 2014.

16. Topcu C, Erdur-Baker O. RCBI-II: The second revision of the revised cyber bullying inventory. Measurement and Evaluation in Counseling and Development. 2018;51(1):32-41. https://doi.org/10.1080/07481756.2017.1395705

17. Tadena S, Kang SR, Kim SJ. The influence of social media affinity on eating attitudes and body dissatisfaction in Philippine adolescents. Child Health Nursing Research. 2020;26(1):121-129. https://doi.org/10.4094/chnr.2020.26.1.121

18. Saito I. Pakikisama: A Filipino trait. [Internet]. Tokyo: Minutes of the Institute of Psychology, Rissho University; 2010 [cited: 2020 October 16]. Available from: https://core.ac.uk/download/pdf/268585067.pdf

19. Witkus SG. Cyber bullying among Filipino adolescents [Internet]. Honolulu: University of Hawaii at Manoa; 2012 [cited: 2020 October 16]. Available from: http://hdl.handle.net/10125/100793

20. Liwag ME, de la Cruz AS, Macapagal ME. How we raise our daughters and sons: Child-rearing and gender socialization in the Philippines. Philippine Journal of Psychology. 1998;31(1-4):1-46.

21. Vitto C. Cyberbullying among adolescents: Frequency and characteristics. Sociol International Journal. 2018;2(6):730-734. https://doi.org/10.15406/sij.2018.02.00129

22. Antoniadou N, Kokkinos C. Empathy in traditional and cyber bullying/victimization involvement from early to middle adolescence: A Cross Sectional Study. Journal of Educational and Developmental Psychology. 2018;8(1):153-161. https://doi.org/10.5539/jedp.v8n1p153

23. Beadle JN, de la Vega CE. Impact of aging on empathy: Review of psychological and neural mechanisms. Frontiers in Psychiatry. 2019;10:331. https://doi.org/10.3389/fpsyt.2019.00331

24. Vitto C, Arslan A. Prevalence of cyberbullying among university students: A comparison between Philippines and Turkey [master's thesis]. Sakarya: Sakarya University; 2018. p. 1-81.

25. Salmon S, Turner S, Taillieu T, Fortier J, Afifi TO. Bullying victimization experiences among middle and high school adolescents: Traditional bullying, discriminatory harassment, and cybervictimization. Journal of Adolescence. 2018;63:29-40.

https://doi.org/10.1016/j.adolescence.2017.12.005

26. Del Rey R, Lazuras L, Casas JA, Barkoukis V, Ortega-Ruiz R, Tsorbatzoudis $\mathrm{H}$. Does empathy predict (cyber) bullying perpetration, and how do age, gender and nationality affect this relationship? Learning and Individual Differences. 2016;45:275-281. https://doi.org/10.1016/j.lindif.2015.11.021

27. Pettalia JL, Levin E, Dickinson J. Cyberbullying: Eliciting harm without consequence. Computers in Human Behavior. 2013;29(6): 2758-2765. https://doi.org/10.1016/j.chb.2013.07.020

28. Almeida A, Correia I, Marinho S, Garcia D. Virtual but not less real: A study of cyberbullying and its relations to moral disengagement and empathy. In: Li Q, Cross D, Smith PK, editors. Cyberbullying in the global playground: Research from international perspectives. Hoboken, NJ: Wiley-Blackwell; 2012. p. 223-244.

29. Elipe P, Mora-Merchán JA, Ortega-Ruiz R, Casas JA. Perceived emotional intelligence as a moderator variable between cybervictimization and its emotional impact. Frontiers in Psychology. 2015; 6:486. https://doi.org/10.3389/fpsyg.2015.00486

30. Machackova H, Pfetsch J. Bystanders' responses to offline bullying and cyberbullying: The role of empathy and normative beliefs about aggression. Scandinavian Journal of Psychology. 2016;57(2): 169-176. https://doi.org/10.1111/sjop.12277 